\title{
EDITORIAL
}

\section{With all the new treatment regimens, complete elimination of hepatitis $C$ virus in Canada is a possibility! But when will Canadians have access to these drugs?}

\author{
Kevork M Peltekian MD FRCPC
}

$F^{i}$ inally, we will be able to achieve sustained viral response (SVR) in patients chronically infected with hepatitis $\mathrm{C}$ virus (HCV) using several interferon-free, all-oral, short-course antiviral regimens. This is a welcome proposition, not only for patients, but also for all of our 'traditional' HCV treating practitioners, namely, gastroenterologists, hepatologists, infectious disease specialists and nurses. At first glance, the direct-acting antiviral agents (DAAs), including inhibitors of NS3/4A protease, NS5A, and both nucleoside and non-nucleoside NS5B polymerase inhibitors, the long list looks daunting. The concise review by Yau and Yoshida (1) (pages 445-451) in the current issue of the Journal summarizes the interferon-free regimens available now or in the near future. There are multiple DAA combinations with potent efficacy ( $>95 \%$ SVR rates), pan-genotypic coverage, high resistance, minimal side effects, and concurrently demonstrating favourable features of low pill burden, short treatment duration and few drug interactions. The pharmaceutical industry will attempt to package and market these DAA combinations for $\mathrm{HCV}$ in the simplest possible way, similar to what they did when the different combination regimens for the treatment of Helicobacter pylori were offered (2). The optimal antiviral regimen will likely include a combination of an NS5B nucleotide polymerase inhibitor with either a second-generation NS3/4A protease inhibitor or NS5A replication complex inhibitor (1).

$\mathrm{HCV}$ is a major cause of liver cirrhosis and hepatocellular carcinoma worldwide. Although HCV is significantly more common than HIV/ AIDS among global populations, it tends to be less well recognized. Approximately 170 million people ( $3 \%$ of the world's population) are chronically infected with HCV. By comparison, it is estimated that there are 40 million HIV carriers. In Canada, nearly 250,000 individuals are viremic with HCV (3). Over the next two decades, this cohort will require a $60 \%$ increase in total health care spending associated with $\mathrm{HCV}$ as result of developing cirrhosis and its complications. The lifetime cost of a Canadian patient with HCV infection (excluding antiviral treatments) is estimated to be $\$ 64,694$ (3). Not surprisingly, most media coverage of these recent developments in HCV treatment has not focused on the high SVR rates but, rather, on cost (4). These regimens of DAA combinations will have a one-time cost between $\$ 50,000$ and $\$ 120,000$ for a course of HCV treatment. Although the price for HCV treatment with DAA combinations may be high, it is less than the cost of life-long therapies for suppression of HIV viral load with antiviral agents, or management of inflammatory bowel disease with biologic and immunosuppressive agents (5).

We have come a long way since the discovery of HCV 25 years ago (6). The development of DAAs has revolutionized HCV treatment by offering real prospects for elimination of a chronic viral infection. It is unfortunate that $\mathrm{HCV}$ vaccine research has lagged. Vaccination will be an important cost-effective alternative or complementary tool for the global eradication of $\mathrm{HCV}$, especially in developing countries. Despite the genetic and antigenic diversity of $\mathrm{HCV}$, substantial progress has been made, yielding several candidates for trials in high-risk populations (7). In these critical times, Canadian public health agencies should take a more prominent role in the management of $\mathrm{HCV}$ and also in research on public health policy, as advocated by the National CIHR Research Training Program in Hepatitis C (8). Effective HCV screening remains the cornerstone for elimination of HCV in Canada. The Canadian Liver Foundation advocates testing for HCV among 'baby boomers' (9), the Canadian birth-cohort from 1945 to 1970. 'Test and treat' strategies need to be elucidated as part of our attempt to eliminate HCV in Canada.

The Canadian health care system needs to adjust quickly to make these high-priced HCV medications available for treating all HCVinfected subjects. Testing high-risk populations without treating them will not help. The Canadian experience with the introduction of the first-generation DAAs boceprevir and telaprevir exposes the slow bureaucracy at both the federal and provincial levels to bring HCV treatments to patients (Figure 1). The time from submission of application

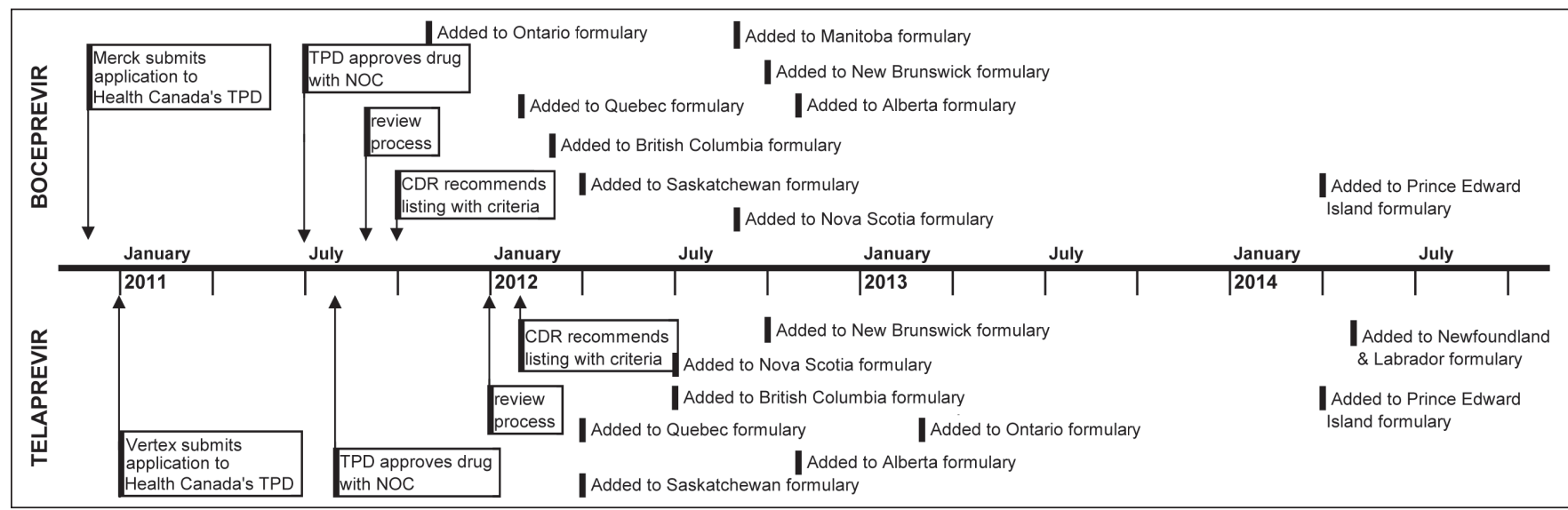

Figure 1) Timelines for approval and listing of boceprevir and telaprevir for hepatitis $C$ in Canada. CDR Common Drug Review within the Canadian Agency for Drugs and Technologies in Health; NOC Notice of compliance; TDR Therapeutic Products Directorate

${ }^{1}$ Department of Medicine, Division of Digestive Care $\mathcal{E}$ Endoscopy, Dalhousie University and Queen Elizabeth II Health Sciences Centre, Halifax, Nova Scotia

Correspondence: Dr Kevork M Peltekian, Atlantic Hepatology Services Inc, PO Box 60010, Halifax, Nova Scotia B3H 4R7.

Telephone 902-473-7833, fax 902-473-4406, e-mail kevork.peltekian@dal.ca

Received and accepted for publication August 15, 2014 
to Health Canada's Therapeutic Products Directorate to listing of boceprevir in provincial drug formularies took a median of 21 months (range 11 to 40 months); boceprevir is still not on the Newfoundland and Labrador drug formulary. For telaprevir, the time was a median of 21 months (range 15 to 40 months) and telaprevir is still not on the Manitoba drug formulary. In Canada, effective approaches to control

\section{REFERENCES}

1. Yau AHL, Yoshida EM. Hepatitis C drugs: The end of the pegylated interferon era and the emergence of all oral, interferon-free antiviral regimens: A concise review. Can J Gastroenterol Hepatol 2014;28:445-51.

2. Rodgers C, Veldhuyzen van Zanten S. A meta-analysis of the success rate of Helicobacter pylori therapy in Canada. Can J Gastroenterol 2007;21:295-300

3. Myers RP, Krajden M, Bilodeau M, et al. Burden of disease and cost of chronic hepatitis C infection in Canada. Can J Gastroenterol Hepatol 2014;28:243-50.

4. Favaro A, St Philip E. Hepatitis C drugs show promise, but price is too high for most patients. <www.ctvnews.ca/health/hepatitis-cdrugs-show-promise-but-price-is-too-high-for-mostpatients-1.1837917> (Accessed August 14, 2014).

5. Marshall JK. Funding the new biologics - CCOHTA report on the cost-effectiveness of infliximab for Crohn's disease: Pearls and pitfalls. Can J Gastroenterol 2002;16:877-9. costs for high-priced medications need to be developed and evaluated to ensure broad, equitable and appropriate use of these new interventions in an already stressed health care system. We hope these new $\mathrm{HCV}$ treatments reach those who need them most without resorting to political pressure and community mobilization.

6. Choo QL, Kuo G, Weiner AJ, Overby LR, Bradley DW, Houghton M. Isolation of a cDNA clone derived from blood-borne non- $\mathrm{A}$, non- $\mathrm{B}$ viral hepatitis genome. Science 1989;244:359-62.

7. Shi C, Ploss A. Hepatitis $\mathrm{C}$ virus vaccines in the era of new directacting antivirals. Expert Rev Gastroenterol Hepatol 2013;7:171-85.

8. Grebely J, Bilodeau M, Feld JJ, et al. The second Canadian symposium on hepatitis $\mathrm{C}$ virus: A call to action. Can J Gastroenterol 2013;27:627-32.

9. Canadian Liver Foundation. National Hepatitis C Survey Prompts Call for All Canadian Boomers to Get Tested: Information gaps may be compromising optimal diagnosis and treatment. <www.liver.ca/ newsroom/press-releases/29-01_2013_CLF_recommends_hepC_ testing.aspx $>$ (Accessed August 14, 2014). 


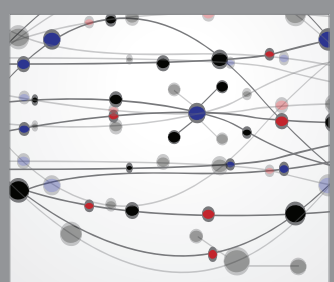

The Scientific World Journal
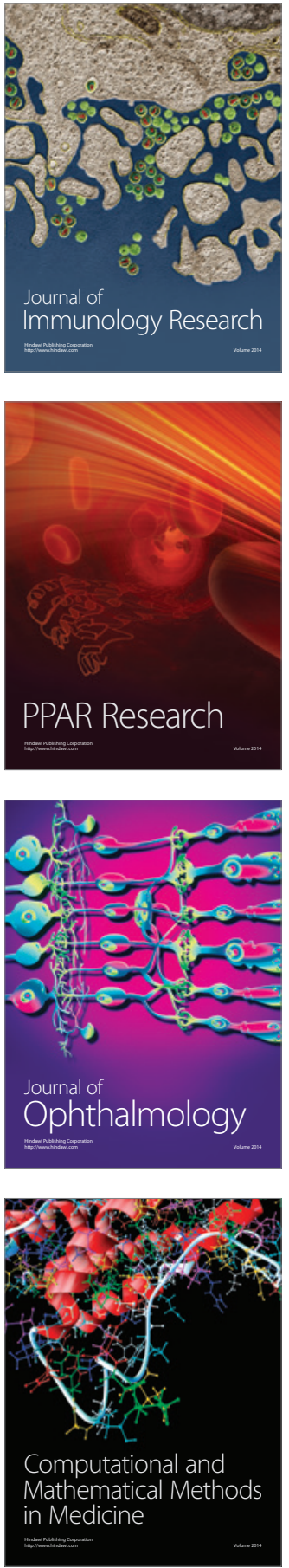

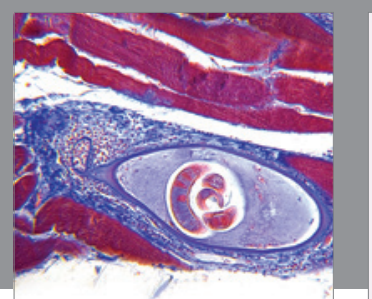

Gastroenterology Research and Practice

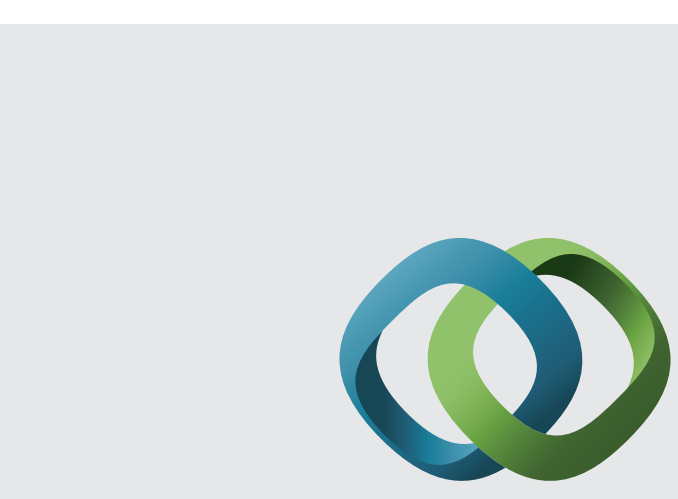

\section{Hindawi}

Submit your manuscripts at

http://www.hindawi.com
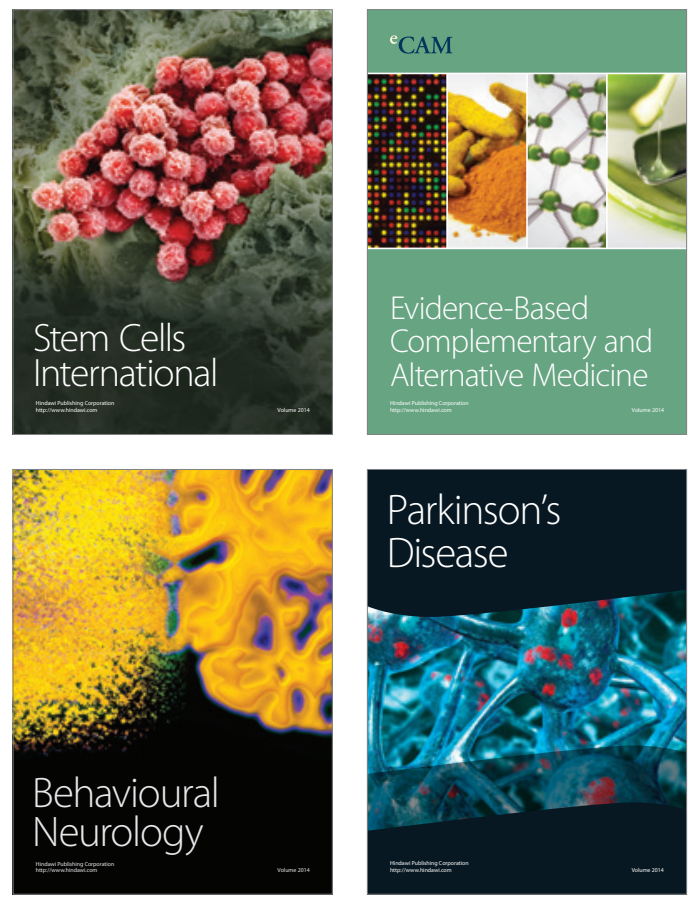
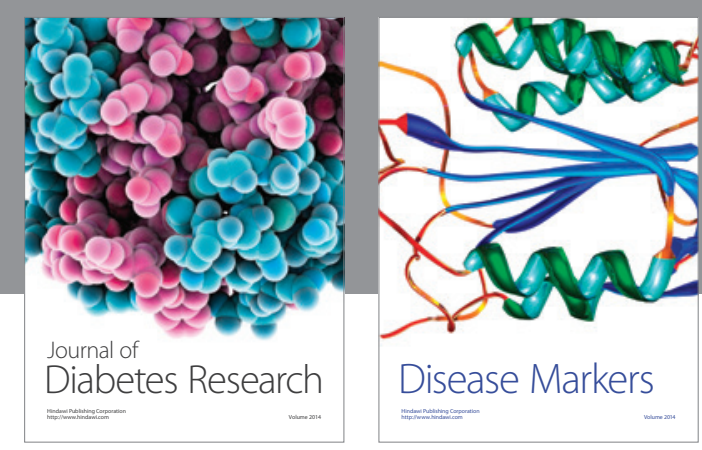

Disease Markers
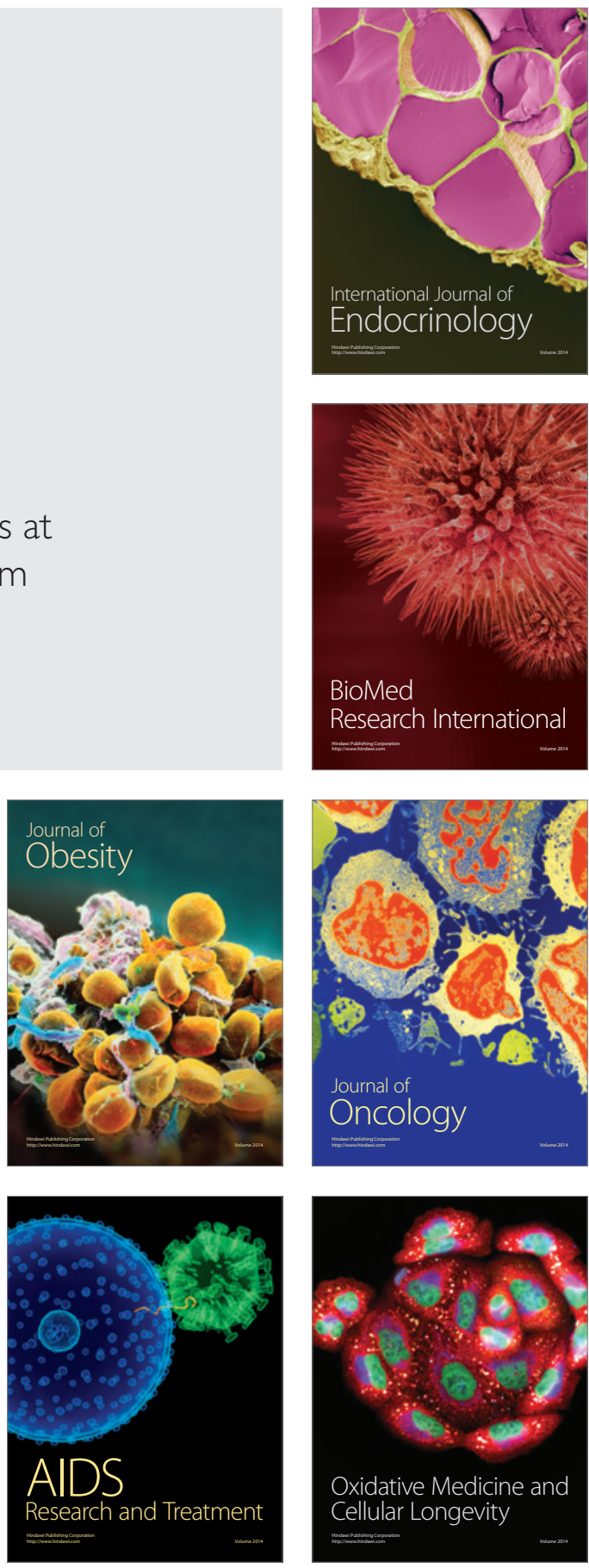